\title{
Comparing the use of Arabic decision aid to usual care
}

\section{A multicenter randomized controlled trial for Arabic speaking metastatic colorectal cancer patients in Saudi Arabia}

Aeshah I. AlSagheir, SBFM, ABFM, Norah A. Alrowais, Msc, FKSU, Basema Kh. Alkhudhair, DPHC, ABFM, Nada A. AlYousefi, SBFM, ABFM, Ahmed I. Al Sagheir, ABIM, FRCP(c), Asma M. Ali, ABIM, FRCP(c), Amel AlMakoshi, MSc, PhD.

\begin{abstract}

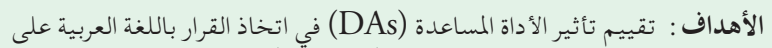

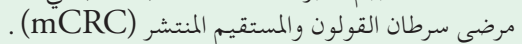

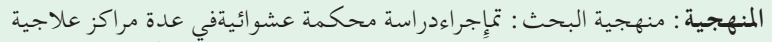

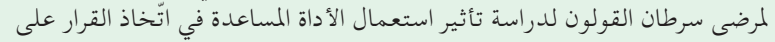

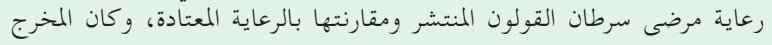

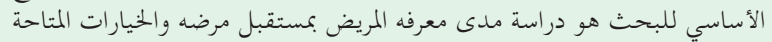

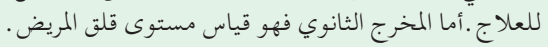

النتائج : عدد المرضي الذين شملتهم الدراسة كان 92 مريضًا حيث تم استعمال

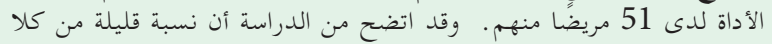

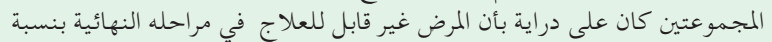

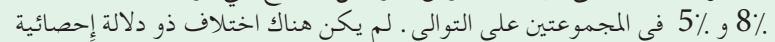

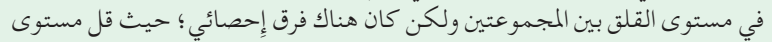

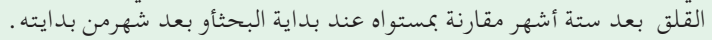

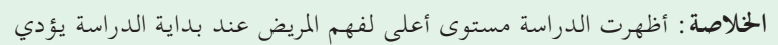

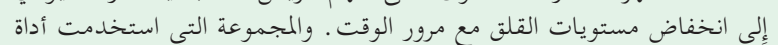

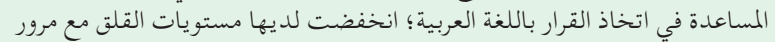

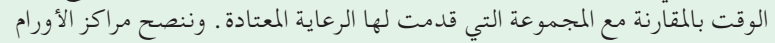

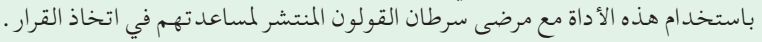

Objectives: To evaluate the effect of decision aids (DAs) for metastatic colorectal cancer (mCRC) patients in the Arabic language.

Methods: A multi-centered randomized control trial was used to evaluate the effect of Arabic DA use with usual care for mCRC patients compared to usual care alone. Patients were recruited from 4 main oncology centers in Saudi Arabia: King Fahad Medical City, Riyadh; King Khalid University Hospital, Riyadh; King Saud Medical City, Riyadh; and King Fahd Specialist Hospital, Dammam, Saudi Arabia, between March 2016 and October 2018. The final follow up was in April 2019. The study measured patient understanding of prognosis, treatment options, and the level of the patient's anxiety.
Results: Ninety-two patients were included in the analysis; 51 in the intervention group. A small proportion of both (DA with usual care and usual care) understood that $\mathrm{mCRC}$ was incurable ( $8 \%$ and $5 \%$ ) of the 2 groups, respectively. There was no significant difference between groups in anxiety level; however, a time effect both initially and after one month was significantly higher than at 6 month.

Conclusion: The study shows that a higher level of patient's baseline understanding lowered anxiety levels over time. Decision aids group presented low levels of anxiety over time than those provided the usual care. We recommend using Arabic DA in the oncology centers dealing with mCRC patients, aiming to empower patients in decision making.

Keywords: antineoplastic agents, anxiety, colorectal neoplasms, decision making, decision support techniques, humans, patient care management, patient education as topic, patient participation, patient satisfaction, Saudi Arabia

Saudi Med J 2020; Vol. 41 (5): 499-507 doi: $10.15537 /$ smj.2020.5.25064

From the Ministry of Health (AlSagheir AI, Khudhair); from the Department of Family and Community Medicine (Alrowais, AlYousefi), College of Medicine, King Saud University, Riyadh; from the Johns Hopkins Aramco Healthcare Oncology Institute (Al Sagheir AH), Dhahran; General Directorate of Medical Services of the Armed Forces (Almakoshi), Ministry of Defense, Riyadh, Kingdom of Saudi Arabia; and from the Northeast Cancer Centre (Ali), Ontario, Canada.

Received 6th December 2019. Accepted 6th April 2020.

Address correspondence and reprint request to: Dr. Aeshah $I$. Al-Saghier, Assistant Director General of Home Health Care Administration, Ministry of Health, Riyadh, Kingdom of Saudi Arabia. E-mail:aal-sagheir@moh.gov.sa / ayshah2000@gmail.com ORCID ID: https://orcid.org/0000-0002-6143-9506 
$\mathrm{C}$ olorectal cancer (CRC) is the most common cancer in men and the third most common in women in Saudi Arabia. In 2014, colorectal cancer accounted for $11.5 \%$ of all newly diagnosed cases among Saudi nationals. ${ }^{1}$ It is the second leading cause of death from cancer. The median survival time for patients with metastatic colorectal cancer (mCRC) is 1-3 years. ${ }^{2}$ The care for patients with mCRC is challenging, and needs to be balanced in terms of efficacy and toxicity when deciding whether to offer aggressive treatments to patients with incurable cancer including standard chemotherapy, targeted therapy, immunotherapy, radiation treatment, and surgery. The decision-making process can be challenging. ${ }^{3}$ Cancer patients are keen to understand comprehensive information about their disease and prognosis and wish to be actively involved in treatment decisions. ${ }^{4}$ Historical data suggests that a large number of patients with advanced cancer do not understand their prognosis even when provided with the information. ${ }^{4}$ They can have unrealistic expectations that their cancer will be cured. ${ }^{5}$ In a study conducted by Weeks et $\mathrm{al}^{6}$ on 1193 patients, $81 \%$ of patients with advanced colorectal cancer did not understand that chemotherapy was unlikely to cure their cancer. Patients may choose aggressive treatments and invasive procedures with little or no benefit that may result in multiple emergency room visits, intensive care stays, and/or hospital admissions. ${ }^{5,7}$ Several physician and patient factors may contribute to the patient's misunderstanding such as communication issues, information overload, fear, anxiety, denial, physicians' reluctance to clearly discuss prognosis, and pressure from family members. ${ }^{5}$ Better understanding may lead to discussions on palliation and strategies to improve their quality of life sooner. ${ }^{5,7,8}$ The use of a DA in patients with advanced CRC can improve patient understanding of their prognosis, treatment options, risks, and benefits without increasing anxiety. ${ }^{3}$ The necessity of translated options to other languages has been addressed in some studies, ${ }^{9,10}$ and no DA has yet been used or tested on Arabic speaking population.

Disclosure. Authors have no conflict of interests, and the work was not supported or funded by any drug company. The authors have no conflict of interests. This work was supported and funded by King Abdulaziz City for Science and Technology (KACST), Riyadh, Saudi Arabia.
This study addressed one crucial question: Are DAs alongside usual care more effective at improving disease understanding and decreasing anxiety than the usual standard care for Arabic-speaking patients with mCRC who are considering first line chemotherapy.

Methods. A multi-centered randomized control trial (RCT) was used to evaluate the effect of an Arabic language decision aid (DA) created for metastatic colorectal cancer (mCRC) patients on their understanding of $\mathrm{mCRC}$ and anxiety levels. The study commenced in March 2016 and recruited its last patient in October 2018. Follow up was completed in April 2019.

Potential study participants were evaluated by the oncology clinic nurse through hospital referral or clinic appointment. Once a patient was identified as meeting the study inclusion criteria (seen below), they were asked to participate in the RCT. Written informed consent was provided by patient or their guardian; their chart was marked with a study label indicating that the patient was participating in a clinical trial. Each participant was allocated to a predetermined randomized arm based on the recruitment entry number.

All who met the following inclusion were recruited: age between 21 and 75 years of age; confirmed diagnosis of metastatic carcinoma of the colon or rectum; patient or companion must be able to read and write; written informed consent is obtained from each patient.

Patients were excluded from the study if they: were not a candidate for chemotherapy because of medical reasons; had previously received chemotherapy for mCRC (adjuvant chemotherapy permitted); were illiterate and/or cognitively impaired; had an uncontrolled psychiatric condition or any other condition that impairs ability to make decisions (namely dysphasia, severe comorbid illness, extreme anxiety, or distress, as assessed by the treating physician); had a life expectancy less than 6 weeks.

Patients were recruited from 4 main oncology centers in Saudi Arabia: King Fahad Medical City (KFMC), Riyadh; King Khalid University Hospital (KKUH), Riyadh; King Saud Medical City (KSMC), Riyadh; and King Fahd Specialist Hospital, Dammam (KFSH-D). The RCT attained ethical approval from all participating hospital Research Ethics Board (IRB) to introduce the DA tool that would be used in addition to the usual care.

The Ottawa Decision Support Framework was used as a reference ${ }^{11}$ to develop a video-based decision aid specifically for this randomized control trial in the Arabic Language. The framework of the Ottawa 
decision support tool lists the 2 treatment options (with or without chemotherapy), and it presents the treatment benefit, response rates, and estimated survival rates. The information was presented using graphic illustrations and numeric estimates. The tool was developed to complement usual care rather than replace the consultation provided by the physician.

The primary outcome for this study was to evaluate the patient's understanding of $\mathrm{mCRC}$ prognosis and treatment information. Patient's understanding was assessed using a questionnaire that covered the natural history of colorectal cancer, its recurrence, and the benefits, risks, and survival outcomes associated with chemotherapy by response options of 'Yes, No, and I do not know'. ${ }^{12}$ The questionnaire was in Arabic and was piloted on 20 patients to ensure language comprehension before use. The scoring was based on the percentage of correct responses to determine the level of understanding on the impact and adverse effects of chemotherapy. Understanding was grouped into 4 domains: First, chemotherapy-induced toxicity which includes fever (more than 38 degrees) and severe diarrhea (more than 6 times above normal) with "Yes" as the correct answer. Painful numbness in the limbs and skin ulcers in the feet and hands (allergies) had "No" as the correct answer. The second outcome with chemotherapy includes chemotherapy helps people live longer and chemotherapy helps you overcome some of the symptoms and problems you experience as "Yes". Third outcome without chemotherapy, which includes the following: my condition will worsen without chemotherapy as "Yes". Finally, the goal was to understand that the disease is incurable; chemotherapy helps full recovery from cancer as "No" The percentage of correct answers was calculated as the number of correct answers in the domain by the number of all answers in the same domain.

The assessment of patient understanding was measured at baseline and included a repeat measurement at one month to assess how much information patients had retained. Patient understanding at baseline was collected from the total RCT sample population; however, the follow-up at one month was a partial sample of the total due to a misinterpretation repeated outcome measurement collection. As such, a correction to collect one month was initiated once identified. While a repeated measure at 6 months was viewed to reflect experience rather than understanding.

The second outcome measure was patient anxiety levels. For patient anxiety, the general anxiety disorder-7 (GAD7) was chosen after extensive review of available literature. ${ }^{13}$ The tool has been validated for use in both the English and Arabic language. ${ }^{14}$ General anxiety disorder-7 is the most common version and includes 7 items for assessing anxiety disorder. All items are rated on a 4-point scale 0-3 (namely "not at all", "several days", "more than half the days" and "nearly every day"). The higher scores are an indication of greater anxiety. The GAD7 is user-friendly for those with at least a sixth-grade reading level, and the overall Cronbach's alpha was 0.91 . The total score for the 7 items range from 0 to 21 . These are split into levels of anxiety. ${ }^{15}$ The levels of anxiety are split into 4 groups: i) 0-4 minimal anxiety; ii) 5-9 mild anxiety; iii) 10-14 moderate anxiety; iv) 15-21 severe anxiety.

Each study participants provided their sociodemographic data and disease characteristics at baseline along with evaluation of anxiety level through GAD7. This took place immediately after their consultation with the physician to assess their understanding and anxiety level. At this point, the study participant reached their initial decision toward a treatment option. At one month and then 6 months' post-treatment decision, a repeated measure was collected regarding anxiety levels of study participants.

Power calculations indicated that 90 patients were needed. The outcome variable for anxiety level was measured by GAD7 with a seven-item range score from not at all as 0 and nearly every day as 3 , with minimum score of 0 and a maximum of 21 . At least 45 subjects were needed to detect a difference in the mean GAD7 score between decision aid and usual care of at least 3 points with a standard deviation of 5 at $80 \%$ power and 5\% alpha. This calculation used Pi face.

The allocation of each study participant was through a computer-generated stratified randomization lists as a case (DA with usual care) or control arm (usual care alone) for each participating hospital. The RCT design did not require the health care providers and participants to be blinded due to the nature of the study; the DA is administered as an intervention in the form of video-based informational tool. The DA tool provided a coherent description of prognosis, diagnosis and treatment options as covered in usual care by an oncologist. The oncologists were informed of patient allocation of randomization arm only after the patient received the DA or usual care. Patients allocated to the DA arm were counseled not to share it with others in the waiting room to avoid contamination of information with those in the control arm.

Statistical analysis. Descriptive statistics were used to describe the patient population including frequencies and percentages for categorical data as well as mean and standard deviation for numerical data. All analyses were 
performed on an intent-to-treat basis. A non-parametric Wilcoxon signed ranks test was used to compare the anxiety level score by study time while Mann-Whitney and Kruskal-Wallis tests were used to study the effect of baseline characteristics on patient understanding scale. Multivariate analysis used linear mixed models for repeated measures (anxiety level). Statistical analysis was performed with IBM SPSS Statistics for Windows, Version 20.0. Armonk, NY: IBM Corp. The test was considered significant if $p<0.05$.

Results. A total number of 99 patients were assessed for eligibility and recruited from 4 cancer centers in Saudi Arabia. Two patients were found to be ineligible while 5 refused to participate. The total number of patients included in the analysis was 92 . Patient randomization and status throughout the study is presented in Figure 1; 55\% were allocated to the intervention group (DA). Most subjects were from King Khalid University Hospital $(\mathrm{n}=35 ; 38 \%)$ and King Fahad Medical City $(\mathrm{n}=32,34.8 \%)$. Approximately $74 \%$ of patients completed all studies for 6 months, and dropout was mainly due to patient's death. There was no significant association between completing the study and any sociodemographic characteristics.

The sociodemographic characteristics of the 2 groups are shown in Table 1 . The mean age \pm SD of all patients was $56.1 \pm 12.3$, and almost two-third were males. Most patients were married, and about half of both groups were residents within 50 kilometers of the health facility with a monthly income of 10,000 Saudi Riyals or less. Half of the sample population had less than a high school education, and $17.4 \%$ were illiterate. Sociodemographic characteristics were not found to be statistically significant between the 2 arms (the minimum $p$-value was for marital status was $p=0.23$ ).

There is no significant difference between the DA $(4.16 \pm 1.23)$ and the usual care $(4.19 \pm 1.15)$ group with respect to the mean overall score of patients understanding scale at baseline $(p=0.86)$. The understanding scale after one month was completed in 26 patients ( $\mathrm{n}=13$ DA and $\mathrm{n}=11$ usual care). There was no significant difference between the 2 arms $(4.85 \pm 1.21$ versus $4.73 \pm 0.79, p=0.45)$. None of the sociodemographic characteristics affected the patients' understanding scale (Table 2).

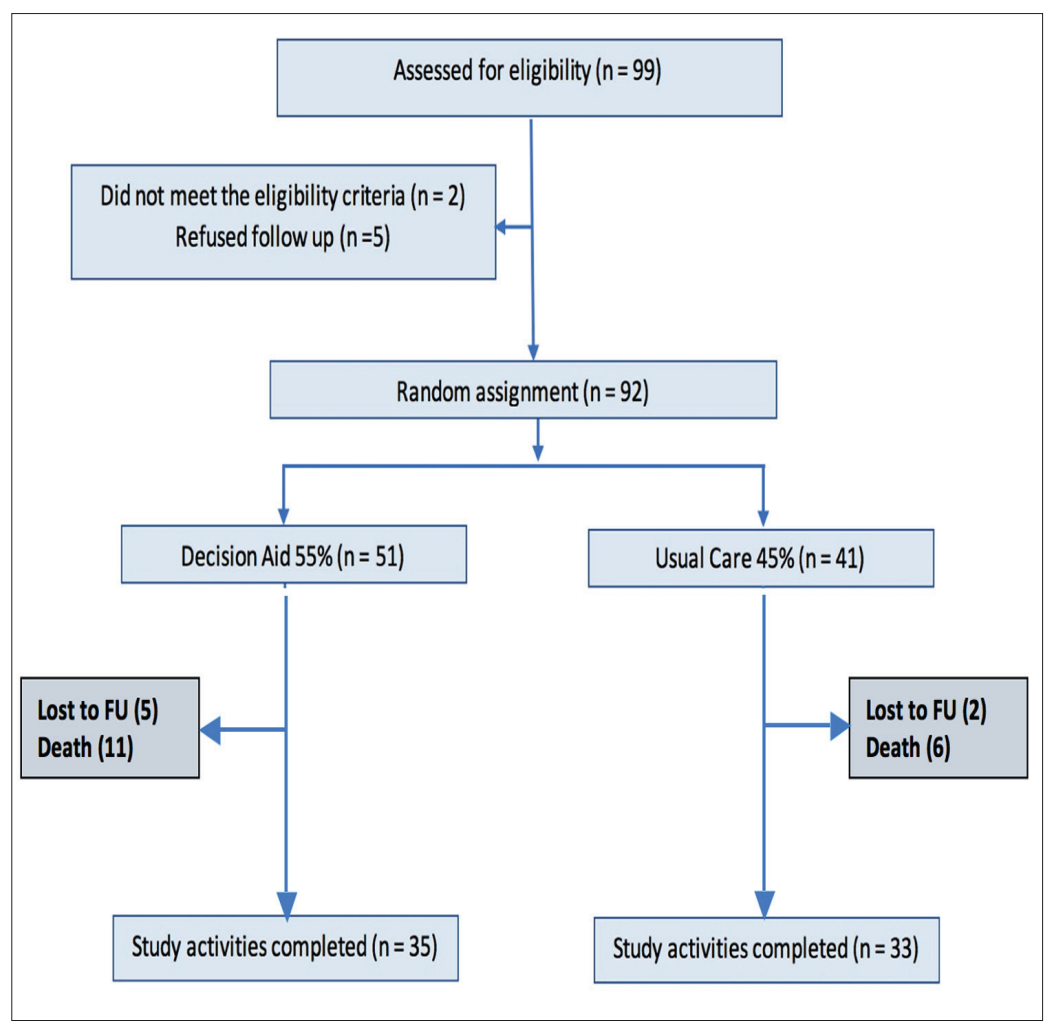

Figure 1 - Randomization and patient's status at the end of the study. 
Arabic decision aid versus usual care ... AlSagheir et al

Table 1 - Sociodemographic characteristics by randomization group.

\begin{tabular}{|c|c|c|c|c|}
\hline \multirow[t]{2}{*}{ Sociodemographic characteristics } & \multicolumn{4}{|c|}{ Randomization group } \\
\hline & $\begin{array}{c}\text { Decision Aid } \\
(\mathbf{n}=51)\end{array}$ & $\begin{array}{c}\text { Usual care } \\
(\mathrm{n}=41)\end{array}$ & & tal \\
\hline Age (years) $($ mean $\pm S D)$ & $55.3 \pm 11.9$ & $57.0 \pm 12.8$ & 56.1 & \pm 12.3 \\
\hline $\begin{array}{l}\text { Gender } \\
\text { Male } \\
\text { Female }\end{array}$ & $\begin{array}{l}37(72.5) \\
14(27.5)\end{array}$ & $\begin{array}{ll}25 & (61.0) \\
16 & (39.0)\end{array}$ & $\begin{array}{l}62 \\
30\end{array}$ & $\begin{array}{l}(67.4) \\
(32.6)\end{array}$ \\
\hline $\begin{array}{l}\text { Marital status } \\
\text { Married } \\
\text { Single } \\
\text { Divorced } \\
\text { Widowed }\end{array}$ & $\begin{array}{rr}34 & (66.7) \\
10 & (19.6) \\
4 & (7.8) \\
3 & (5.9)\end{array}$ & $\begin{array}{rr}32 & (78.0) \\
5 & (12.2) \\
0 & (0.0) \\
4 & (9.8)\end{array}$ & $\begin{array}{r}66 \\
15 \\
4 \\
7\end{array}$ & $\begin{array}{l}(71.7) \\
(16.3) \\
(4.3) \\
(7.6)\end{array}$ \\
\hline $\begin{array}{l}\text { Residence distance }(\mathrm{km}) \text { within } 50 \\
\quad 50-100 \\
\quad 100-200 \\
200-400 \\
>400\end{array}$ & $\begin{array}{rr}26 & (52.0) \\
9 & (18.0) \\
3 & (6.0) \\
4 & (8.0) \\
8 & (16.0)\end{array}$ & $\begin{array}{rr}19 & (46.3) \\
7 & (17.1) \\
3 & (7.3) \\
2 & (4.9) \\
10 & (24.4)\end{array}$ & $\begin{array}{r}45 \\
16 \\
6 \\
6 \\
18\end{array}$ & $\begin{array}{l}(49.5) \\
(17.6) \\
(6.6) \\
(6.6) \\
(19.8)\end{array}$ \\
\hline $\begin{array}{l}\text { Education } \\
\text { Illiterate } \\
\text { Less than high school } \\
\text { High school } \\
\text { Diploma } \\
\text { College graduate } \\
\text { Postgraduate }\end{array}$ & $\begin{array}{rr}6 & (11.8) \\
20 & (39.2) \\
9 & (17.6) \\
6 & (11.8) \\
9 & (17.6) \\
1 & (2.0)\end{array}$ & $\begin{array}{rr}10 & (24.4) \\
13 & (31.7) \\
7 & (17.1) \\
6 & (14.6) \\
5 & (12.2) \\
0 & (0.0)\end{array}$ & $\begin{array}{r}16 \\
33 \\
16 \\
12 \\
14 \\
1\end{array}$ & $\begin{array}{l}(17.4) \\
(35.9) \\
(17.4) \\
(13.0) \\
(15.2) \\
(1.1)\end{array}$ \\
\hline $\begin{array}{l}\text { Monthly income (SAR) } \\
\quad<5000 \\
\quad 5000-10000 \\
10001-15000 \\
>15000\end{array}$ & $\begin{array}{rr}14 & (27.5) \\
25 & (49.0) \\
8 & (15.7) \\
4 & (7.8)\end{array}$ & $\begin{aligned} 15 & (36.6) \\
16 & (39.0) \\
5 & (12.2) \\
5 & (12.2)\end{aligned}$ & $\begin{array}{r}29 \\
41 \\
13 \\
9\end{array}$ & $\begin{array}{c}(31.5) \\
(44.6) \\
(14.1) \\
(9.8)\end{array}$ \\
\hline
\end{tabular}

Table 2 - Patient's understanding scale by randomization and sociodemographic characteristics.

\begin{tabular}{|c|c|c|c|c|c|c|}
\hline \multirow[t]{2}{*}{ Sociodemographic characteristics } & \multicolumn{5}{|c|}{ Understanding scale (out of 8) } & \multirow[t]{2}{*}{$P$-value } \\
\hline & Mean & SD & Median & P25 & P75 & \\
\hline \multicolumn{7}{|l|}{ Randomization group } \\
\hline Decision aid (n=50) & 4.16 & 1.23 & 5.0 & 3.0 & 5.0 & \multirow[t]{2}{*}{0.86} \\
\hline Usual care $(n=40)$ & 4.18 & 1.15 & 4.0 & 3.0 & 5.0 & \\
\hline \multicolumn{7}{|l|}{ Gender } \\
\hline Male & 4.15 & 1.12 & 4.0 & 3.0 & 5.0 & \multirow[t]{2}{*}{0.57} \\
\hline Female & 4.21 & 1.35 & 5.0 & 4.0 & 5.0 & \\
\hline \multicolumn{7}{|l|}{ Age (years) } \\
\hline$<50$ & 3.96 & 1.43 & 5.0 & 3.0 & 5.0 & \multirow{3}{*}{0.46} \\
\hline $50-59$ & 4.39 & 1.06 & 5.0 & 4.0 & 5.0 & \\
\hline$\geq 60$ & 4.09 & 1.14 & 4.0 & 3.0 & 5.0 & \\
\hline \multicolumn{7}{|l|}{ Marital status } \\
\hline Married & 4.18 & 1.20 & 4.0 & 3.0 & 5.0 & \multirow[t]{2}{*}{0.94} \\
\hline Unmarried & 4.12 & 1.20 & 5.0 & 3.0 & 5.0 & \\
\hline \multicolumn{7}{|l|}{ Residence distance (km) } \\
\hline Within 50 & 4.21 & 1.15 & 5.0 & 3.0 & 5.0 & \multirow[t]{2}{*}{0.67} \\
\hline More than 50 & 4.11 & 1.25 & 4.0 & 3.0 & 5.0 & \\
\hline \multicolumn{7}{|l|}{ Education } \\
\hline Illiterate & 4.38 & 0.81 & 5.0 & 4.0 & 5.0 & \multirow{4}{*}{0.58} \\
\hline Less than high school & 4.06 & 1.27 & 4.0 & 3.0 & 5.0 & \\
\hline High school & 4.40 & 1.35 & 5.0 & 4.0 & 5.0 & \\
\hline More than high school & 4.04 & 1.22 & 4.0 & 3.0 & 5.0 & \\
\hline \multicolumn{7}{|l|}{ Monthly income (SAR) } \\
\hline$<5000$ & 4.36 & 1.28 & 5.0 & 4.0 & 5.0 & \multirow{3}{*}{0.29} \\
\hline $5000-10000$ & 4.07 & 1.29 & 4.0 & 3.0 & 5.0 & \\
\hline$>10000$ & 4.10 & 0.83 & 4.0 & 3.0 & 5.0 & \\
\hline
\end{tabular}


Figure 2 illustrates the baseline understanding on mCRC prognosis and treatment outcomes. The understanding of chemotherapy outcomes and effects was understood by more than half the sample population for both randomization arms. Those allocated to the usual care had a better understanding at the initial assessment for outcomes without chemotherapy (75\%) and induced toxicity (58\%). A small proportion of both arms (DA and usual care) understood that stage 4 mCRC was incurable ( $8 \%$ and $5 \%$, respectively).

The total anxiety level score was compared for each randomization group at the 3 time points assessed. In general, the anxiety level decreased with time for both arms. There was a significant reduction in the anxiety

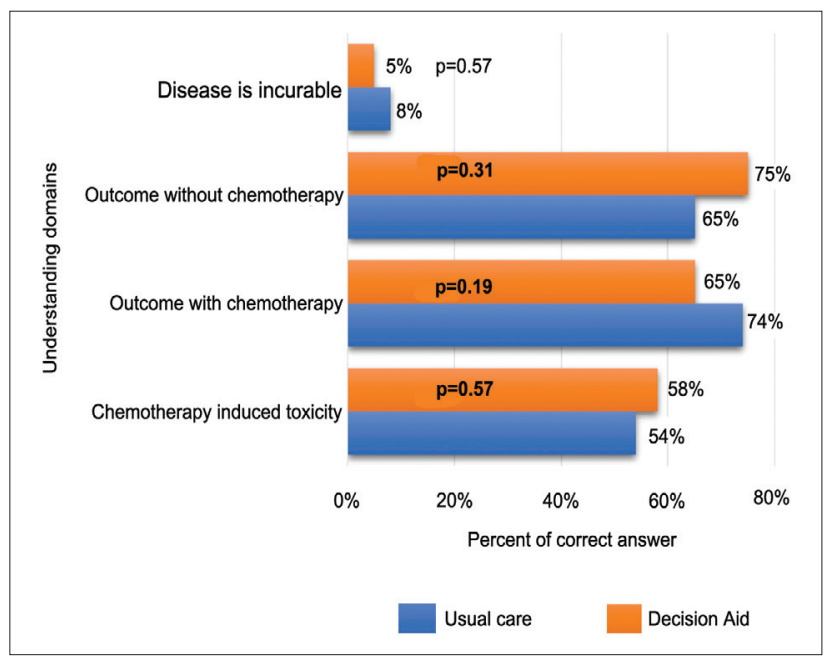

Figure 2 - Patient's understanding scale domains by randomization group. level score at baseline and at six months in both groups. The DA and usual care had mean reductions; 2.27 , $p=0.033$ and $1.94, p=0.045$, respectively. The minimal anxiety scores increased in both groups during the study period. Mild anxiety increased in both groups after 1 month but decreased after six months versus baseline levels. Severe anxiety also decreased in both groups. The minimal and mild anxiety were generally more in the DA group; moderate and severe anxiety were higher in the usual care group (Figure 3A). The error bars show a decline in the mean level of anxiety by time. The understanding scale was categorized into 2 group: low categorized as less than 4 and high categorized as 4 or more. The mean anxiety for patients with low understanding always scored a higher mean anxiety level (Figure 3B).

Next, a linear mixed model (LMM) was applied to test the effect of the study time (initial, one month, and 6 months) on patients' level of anxiety (GAD7) after adjusting for other factors especially knowledge (understanding scale). In the LMM model, there is no significant difference between DA and usual case in the anxiety level, but there is a time effect (both initially and one month). These effects are significantly higher than 6 months later $(p=0.003$ and $p=0.034)$. Moreover, the understanding scale has an inverse relation with anxiety level because the understanding scale increases by one score, and the level of anxiety decreases by approximately a half score. The interaction terms were removed from the model because significant effect $(p>0.05)$ was found. Finally, the module tested the effect of other variables and none of the baseline characteristics had an effect on the anxiety level.

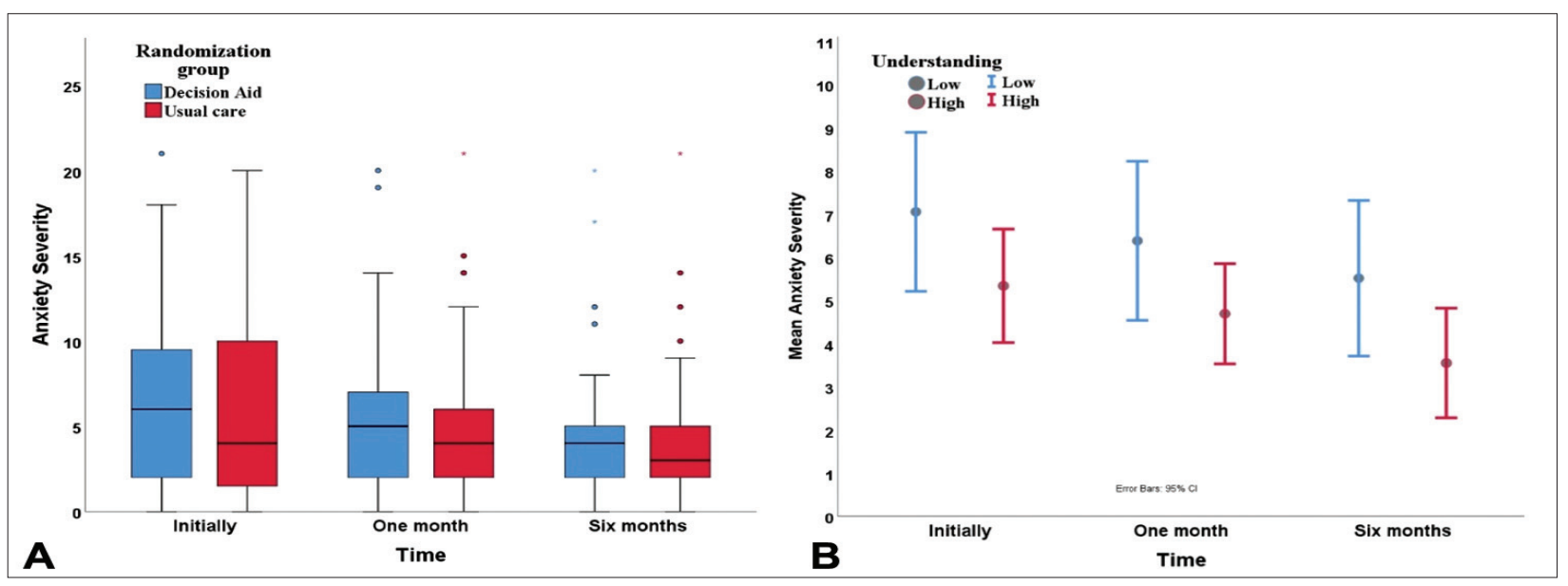

Figure 3 - Anxiety severity scores by A) randomization group and B) understanding scale (low versus high) over study period 
Table 3 - Linear mixed model to test the effect of time, understanding scale, and randomization group on anxiety level.

\begin{tabular}{lcccc}
\hline Variables & Estimate & $P$-value & $\begin{array}{c}\text { 95\% Confidence Interval } \\
\text { Lower }\end{array}$ & Upper \\
\hline Intercept & & & 4.07 & 10.22 \\
$\quad \begin{array}{l}\text { Randomization group } \\
\quad \text { Decision aid }\end{array}$ & 0.42 & 0.628 & -1.30 & 2.15 \\
$\quad 0$ Usual care & (ref) & - & - & - \\
$\quad \begin{array}{l}\text { Time } \\
\quad \text { Initially }\end{array}$ & 1.66 & 0.003 & 0.59 & 2.73 \\
$\quad \begin{array}{l}\text { One month } \\
\text { Six months }\end{array}$ & 0.98 & 0.034 & 0.07 & 1.88 \\
$\quad 0(\mathrm{ref})$ & - & - & - \\
$\quad$ Understanding scale & -0.53 & 0.037 & -1.03 & -0.03 \\
\hline
\end{tabular}

ref: reference group

Discussion. Patients with a new diagnosis of mCRC are required to make complex decisions, including whether to have first-line chemotherapy. In this study, the computerized Arabic Decision Aid intervention was used to measure mCRC understanding of treatment options in a non-pressured environment. It also measured the impact the DA had on patient understanding and anxiety level. Outcomes assessed in this randomized study are meaningful and are less often studied relative to overall survival, disease-free survival, and quality of life.

In a recent systematic review that included 105 studies, DAs improved patient understanding of aggressive and more conservative treatment options and outcomes. They also had a positive effect on patientclinician communication without increasing patient anxiety. ${ }^{16}$ Our data suggest that DA immediately postconsultation resulted in a non-statistically significant improvement in patients' anxiety in terms of the possible benefits. This intervention improved the outcomes of the DA study arm versus patients who only had usual care.

Understanding the treatment intent is important because it allows patients to make informed decisions in accordance with their true wishes. ${ }^{17}$ Physicians dread delivering upsetting news to patients, but the data suggest that patient satisfaction and psychological wellbeing improve when given truthful prognostic information provided that this information is tailored to individual patient preferences sensitively and appropriately. ${ }^{17}$ Decision aids may help physicians relay complex prognostic information to patients, set realistic expectations, and introduce supportive care alone as an option. This study supports these conclusions: high levels of understanding have a positive effect on anxiety levels over time.

Leigh et $\mathrm{al}^{3}$ found no significant difference in patients understanding with advanced colorectal cancer who were assigned to the DA arm versus standard care when assessed post-consultation immediately. Repeat measurement of understanding at one to 2 weeks' postconsultation showed an increase in understanding in both arms, this was more significant in the DA arm, suggesting that patients are overwhelmed, distressed, and likely do not fully understand the situation at the initial consultation. In our study, almost $90 \%$ of patients in both groups had unrealistic expectations that chemotherapy would cure their cancer despite being told that chemotherapy is not being offered with curative intent. Our findings support previous studies reporting that most patients overestimate the benefit of palliative chemotherapy. ${ }^{5}$

Emotions such as anxiety may affect patients' ability to recall information presented at consultation. Such emotions can also affect their thinking process and the choices related to their cancer treatment. ${ }^{18}$ In our study, anxiety scores decreased over time in both groups with no statistically significant difference between them. This finding supports previous studies that reported no increase in patient anxiety levels with the use of DAs. ${ }^{3,16}$ Both baseline understanding and the DA lowered anxiety over time individually; however, when merged, baseline understanding was a strong factor in lowering anxiety regardless of sociodemographic factors.

Sociodemographic characteristics (gender, age, marital status, residence distance to the treatment center, and education level) had no impact on patient understanding except for low income that had a borderline statistical significance and was reported by half of the cohort. More than half of our population reported no or less than high school education. Other studies found variation in care and worse cancer survival in patients with lower incomes and little education. ${ }^{19}$ This information should serve as a strong drive to expand the use of DA and other educational tools to help patients with $\mathrm{mCRC}$ with special attention to the different backgrounds: Visual aids can improve this understanding by providing a more comprehensive explanation.

This study included a repeat measurement of understanding at one-month post-consultation; this 
was seen in around a third of the studied population. However, understanding at baseline and at one month suggested that anxiety levels lower over time. The missing data in our study may have reduced the power to detect a significant difference in understanding between groups this highlights one of the major challenges encountered in conducting studies in Saudi Arabia. ${ }^{20}$

Overall, the DA was well accepted by patients as indicated by the low refusal rate similar to another study carried out on evaluation of a DA for patients with stage IV non-small cell lung cancer. ${ }^{21}$ However, a significant challenge in the continued use of a DA is including the most current evidence, particularly when there are fast advances and changes in cancer treatment modalities. New evidence can be integrated via computer-generated aids, which can also be costeffective and easily distributed.

Study limitations. This project met several challenges due to the length and nature of the RCT and its study population. While the project was initially planned to be completed in 24 months, it took 36 months to recruit all participants. Slow recruitment is a major challenge in clinical trials. According to one report, more than $80 \%$ of clinical trials fail to be on schedule for the target population. ${ }^{22}$ This situation was found to be more difficult in the Middle East with many barriers against clinical trials, ${ }^{13}$ including the limited validated coherent data for annual disease burden. Another challenge found was for 2 summers, the attendance of newly diagnosed mCRC patients to the clinics stopped between the Islamic holidays of Ramadan and Hajj. This challenge would need further study to assess the related factors associated with this.

In conclusion, Arabic language DAs developed for patients with $\mathrm{mCRC}$ who are considering first-line chemotherapy. A high level of baseline understanding lowers anxiety over time despite demographic facts that highlight the importance of health literacy in the treatments of patients.

We recommend using Arabic DA in the oncology centers when dealing with mCRC patients, and the tool itself has the potential to be scripted to a variety of other health diseases. As common with usual care, the DA could be continuously updated in line with advances in therapeutic options. Other research opportunities can be opened regarding the use of decision aid in other diseases. Future research is needed to explore the impact of DAs on the healthcare system.
Acknowledgment. We would like to thank the King Abdulaziz College for Science and Technology (KACST), Riyadh, Saudi Arabia for funding this study.

\section{References}

1. Saudi Health Council. Cancer Incidence Report Saudi Arabia 2014. [cited 2017]. Available from: https://nhic.gov.sa/ eServices/Documents/2014.pdf

2. Venook AP, Niedzwiecki D, Lenz HJ, Innocenti F, Fruth B, Meyerhardt JA, et al. Effect of first-line chemotherapy combined with cetuximab or bevacizumab on overall survival in patients with KRAS wild-type advanced or metastatic colorectal cancer: A randomized clinical trial. JAMA 2017; 317: 2392-2401.

3. Leighl NB, Shepherd HL, Butow PN, Clarke SJ, McJannett M, Beale PJ, et al. Supporting treatment decision making in advanced cancer: a randomized trial of a decision aid for patients with advanced colorectal cancer considering chemotherapy. $J$ Clin Oncol 2011; 29: 2077-2084.

4. Cartwright LA, Dumenci L, Siminoff LA, Matsuyama RK. Cancer patients' understanding of prognostic information. $J$ Cancer Educ 2014; 29: 311-317.

5. Ghandourh WA. Palliative care in cancer: managing patients' expectations. J Med Radiat Sci 2016; 63: 242-257.

6. Weeks JC, Catalano PJ, Cronin A, Finkelman MD, Mack JW, Keating NL, et al. Patients' expectations about effects of chemotherapy for advanced cancer. N Engl J Med. 2012; 367 : 1616-1625.

7. Sineshaw HM, Jemal A, Ng K, Osarogiagbon RU, Robin Yabroff K, Ruddy KJ, et al. Treatment patterns among de novo metastatic cancer patients who died within 1 month of diagnosis. JNCI Cancer Spectr 2019; 3: pkz021.

8. Epstein AS, Prigerson HG, O'Reilly EM, Maciejewski PK. Discussions of life expectancy and changes in illness understanding in patients with advanced cancer. J Clin Oncol. 2016; 34: 2398-2403.

9. Berry DL, Halpenny B, Bosco JLF, Bruyere J, Jr., Sanda MG. Usability evaluation and adaptation of the e-health Personal Patient Profile-Prostate decision aid for Spanish-speaking Latino men. BMC Med Inform Decis Mak 2015; 15: 56.

10. Ko LK, Reuland D, Jolles M, Clay R, Pignone M. Cultural and linguistic adaptation of a multimedia colorectal cancer screening decision aid for Spanish-speaking Latinos. J Health Commun 2014; 19: 192-209.

11. Ottawa Decision Support Framework (ODSF). [cited 2015 June 22]. Available from: https://decisionaid.ohri.ca/odsf.html

12. Deber RB, Kraetschmer N, Irvine J. What role do patients wish to play in treatment decision making? Arch Intern Med. 1996; 156: 1414-1420.

13. Nair SC, Ibrahim H, Celentano DD. Clinical trials in the Middle East and North Africa (MENA) Region: grandstanding or grandeur? Contemp Clin Trials 2013; 36: 704-710.

14. Clayton JM, Butow PN, Tattersall MH, Devine RJ, Simpson JM, Aggarwal G, et al. Randomized controlled trial of a prompt list to help advanced cancer patients and their caregivers to ask questions about prognosis and end-of-life care. J Clin Oncol 2007; 25: 715-723.

15. GAD7 scoring: Anxiety and Depression Association of America. [cited 2015]. Available from: https://adaa.org/sites/default/ files/GAD-7_Anxiety-updated_0.pdf. 
16. Stacey D, Legare F, Lewis K, Barry MJ, Bennett CL, Eden $\mathrm{KB}$, et al. Decision aids for people facing health treatment or screening decisions. Cochrane Database Syst Rev 2017; 4: CD001431.

17. Glatzer M, Panje CM, Siren C, Cihoric N, Putora PM. Decision Making Criteria in Oncology. Oncology 2018; 18: 1-9.

18. Mazzocco K, Masiero M, Carriero MC, Pravettoni G. The role of emotions in cancer patients' decision-making. Ecancermedicalscience 2019; 13: 914.

19. Enard KR, Dolan Mullen P, Kamath GR, Dixon NM, Volk RJ. Are cancer-related decision aids appropriate for socially disadvantaged patients? A systematic review of US randomized controlled trials. BMC Med Inform Decis Mak 2016; 16: 64.
20. Al Suwaidan S AA. Obstacles in conducting clinical trials in the Saudi Arabia. International Journal of Clinical Trials 2017; 4: 166-170.

21. Ong HL, Sokolova I, Bekarma H, Curtis C, Macdonald A, Agur W, et al. Development, validation and initial evaluation of patient-decision aid (SUI-PDA(c)) for women considering stress urinary incontinence surgery. Int Urogynecol J 2019; 30: 2013-2022.

22. Bansal N. The opportunities and challenges in conducting clinical trials globally. Clinical Research and Regulatory Affairs 2012; 29: 9-14.

\section{Withdrawal policy}

By submission, the author grants the journal right of first publication. Therefore, the journal discourages unethical withdrawal of manuscript from the publication process after peer review. The corresponding author should send a formal request signed by all co-authors stating the reason for withdrawing the manuscript. Withdrawal of manuscript is only considered valid when the editor accepts, or approves the reason to withdraw the manuscript from publication. Subsequently, the author must receive a confirmation from the editorial office. Only at that stage, authors are free to submit the manuscript elsewhere.

No response from the authors to all journal communication after review and acceptance is also considered unethical withdrawal. Withdrawn manuscripts noted to have already been submitted or published in another journal will be subjected to sanctions in accordance with the journal policy. The journal will take disciplinary measures for unacceptable withdrawal of manuscripts. An embargo of 5 years will be enforced for the author and their co-authors, and their institute will be notified of this action. 